\title{
DNA metabarcoding provides insights into the diverse diet of a dominant suspension feeder, the giant plumose anemone Metridium farcimen
}

Running title: Metabarcoding and the diverse diet of an anemone

Christopher D. Wells ${ }^{1 *}$, Gustav Paulay ${ }^{2}$, Bryan N. Nguyen ${ }^{3,4}$ and Matthieu Leray 5

1. Department of Geology, University at Buffalo, State University of New York, Buffalo, NY 14260-1300, USA, ORCID: 0000-0002-5945-6171

2. Florida Museum of Natural History, University of Florida, Gainesville, Florida 32611-2062, USA ORCID: 0000-0003-4118-9797

3. Computational Biology Institute, The Milken Institute School of Public Health, George

Washington University, Washington, D.C. 20037-2301, USA, ORCID: 0000-0001-7791-4693

4. Department of Biological Sciences, George Washington University, Washington, D.C. 20052-0066, USA

5. Smithsonian Tropical Research Institute, Smithsonian Institution, Panama City 0843-03092, Republic of Panama, ORCID: 0000-0002-7327-1878

* Email: christopher.wells.23@gmail.com

\begin{abstract}
Benthic suspension feeders have significant impacts on plankton communities by depleting plankton or modifying composition of the plankton through prey selectivity. Quantifying diets of planktivorous animals can be difficult because plankton are frequently microscopic, may lack diagnostic characters, and are digested at variable rates. With DNA metabarcoding, the identification of gut contents has become faster and more accurate, and the technique allows for higher taxonomic resolution-n while also identifying rare and highly degraded items that would otherwise not be detected. We used DNA metabarcoding to examine the diet of the giant plumose anemone Metridium farcimen, a large, abundant, competitively-dominant anemone on subtidal rock surfaces and floating docks in the northeast Pacific Ocean. Gut contents of 12 individuals were compared to 80- and 330- $\mu \mathrm{m}$ filtered plankton samples collected one hour prior between 0.02 and $1.5 \mathrm{~km}$ from the anemones. The objectives of this study were to determine if $M$. farcimen has a selective diet and compare our findings with traditional gut content analyses. Metridium farcimen captured a wider range of prey than previously suspected and metabarcoding found many more taxa than traditional sampling techniques. Gut contents were less diverse than $80-\mu \mathrm{m}$ filtered plankton samples, but more diverse than 330- $\mu \mathrm{m}$ filtered plankton samples. The diet of the anemones was $52 \%$ arthropods with a surprisingly high relative abundance of an ant $(10 \%)$ that has mating flights in August when this study was conducted. The gut contents of $M$. farcimen likely include all prey that it can detect and that cannot escape. There were no overrepresented taxa in the gut contents compared to the plankton but there were underrepresented taxa. This study highlights the usefulness of the metabarcoding method in identifying prey within the gut of planktivorous animals and the significant terrestrial input into marine food webs.
\end{abstract}

Keywords: Anthozoa, benthic-pelagic coupling, Cnidaria, community ecology, DNA Barcoding, ecosystem subsidies, historical comparisons, predation 


\section{INTRODUCTION}

Benthic suspension feeders can have major impacts on the structure of littoral food webs (Gili \& Coma, 1998; Kimmerer, Gartside, \& Orsi, 1994; Petersen, 2004; Sebens \& Koehl, 1984; Whitten, Marin Jarrin, \& McNaught, 2018; Young \& Gotelli, 1988). Dense populations of suspension feeders can filter the immediately overlying water volume several times a day (Davies, Stuart, \& de Villiers, 1989; Jørgensen, 1980; Petersen, 2004; Petersen \& Riisgård, 1992; Riisgård, 1991; Vedel, Andersen, \& Riisgård, 1994) until depleting it from resources (Riisgård, Jürgensen, \& Clausen, 1996; Riisgård, Poulsen, \& Larsen, 1996; Vedel, 1998).

Both passive and active benthic suspension feeders rely on water flow to bring food particles to their vicinity. Yet, all prey do not have equal probability of being captured. Prey use mechanisms such as escape behaviors, morphological defenses, and toxicity to avoid predation (Browman, Kruse, \& O'Brien, 1989; Dodson, 1974; Engström, Viherluoto, \& Viitasalo, 2001; Safi, Hewitt, \& Talman, 2007; Suchman \& Sullivan, 1998; Viitasalo, Flinkman, \& Viherluoto, 2001; Viitasalo, Kiørboe, Flinkman, Pedersen, \& Visser, 1998). In addition, numerous suspension feeders are highly selective for certain types of prey. Many bivalves, for example, preferentially select plankton based on size, shape, and motility (Cucci et al., 1985; Defossez \& Hawkins, 1997; Safi et al., 2007; Shumway, Cucci, Newell, \& Yentsch, 1985). Prey selectivity can result from the inability of predators to capture certain prey, the preferential capture or consumption of palatable and energetically valuable species, or active rejection of prey. Studies on the dietary selectivity of benthic suspension feeders are key to our understanding of the effects of predators on their ecosystem and of the role of dietary niche partitioning for species coexistence (Costello \& Colin, 2002; Leray et al., 2019; Suchman \& Sullivan, 1998).

Unfortunately, quantifying the diet of planktivorous animals can be difficult because plankton are frequently microscopic, often lack diagnostic characters, are digested quickly and at variable rates, and resources for identification are poorly developed for most regions (Fancett, 1988; Larson, 1991; Purcell, 1977; Sebens \& Koehl, 1984; Zamer, 1986). Because of this, marine plankton are difficult to identify in gut contents past the class or order level when using traditional visual identification techniques (e.g., Fancett, 1988; Purcell, 1977; Sebens \& Koehl, 1984).

With the advent of high throughput sequencing and powerful molecular techniques such as DNA metabarcoding (Taberlet, Coissac, Pompanon, Brochmann, \& Willerslev, 2012), identification of specimens within community samples, such as in plankton and gut contents, can be rapid, accurate, and relatively cheap (Aylagas, Borja, \& Rodríguez-Ezpeleta, 2014; BrandonMong et al., 2015; Nielsen, Clare, Hayden, Brett, \& Kratina, 2018). DNA metabarcoding has been used to successfully identify taxa within gut contents of fishes (Albaina, Aguirre, Abad, Santos, \& Estonba, 2016; Harms-Tuohy, Schizas, \& Appeldoorn, 2016; Leray, Meyer, \& Mills, 2015; Leray, Yang, et al., 2013), to evaluate biodiversity of insects (Brandon-Mong et al., 2015; Ji et al., 2013; Yu et al., 2012), and to identify the presence of rare taxa using environmental DNA (Deiner et al., 2017; Evans et al., 2016; Valentini et al., 2016). Metabarcoding can be used to analyze diets to reach a higher taxonomic resolution while also identifying rare and highly degraded items that would otherwise not be detected (Nielsen et al., 2018).

We used DNA metabarcoding to examine the diet of the giant plumose anemone Metridium farcimen (Brandt, 1835, Fig. 1). Metridium farcimen (Cnidaria, Anthozoa, Actiniaria) is a large, abundant sea anemone on subtidal rock surfaces and floating docks in the northeast Pacific Ocean (Fautin, Bucklin, \& Hand, 1989; Fautin \& Hand, 2000; Hand, 1955; Kozloff, 1973; Ricketts, Calvin, \& Hedgpeth, 1968) that feeds on small zooplankton (Koehl, 1977a; Purcell, 1977; Sebens, 
1981; Shick, 1991). This anemone, which can extend over a meter into the water column (Fautin et al., 1989), is well-adapted for high-flow environments (Koehl, 1977a, 1977b, 1977c) and is a competitive dominant species on rocky subtidal ledge communities (Nelson \& Craig, 2011; Wells, 2019; Wells \& Sebens, 2017). Gut contents of M. farcimen in the San Juan Archipelago, WA, USA were compared to concurrent, nearby plankton samples to determine if $M$. farcimen has a selective diet and to compare findings from traditional gut content analyses (i.e., suction and dissection) with metabarcoding analysis.

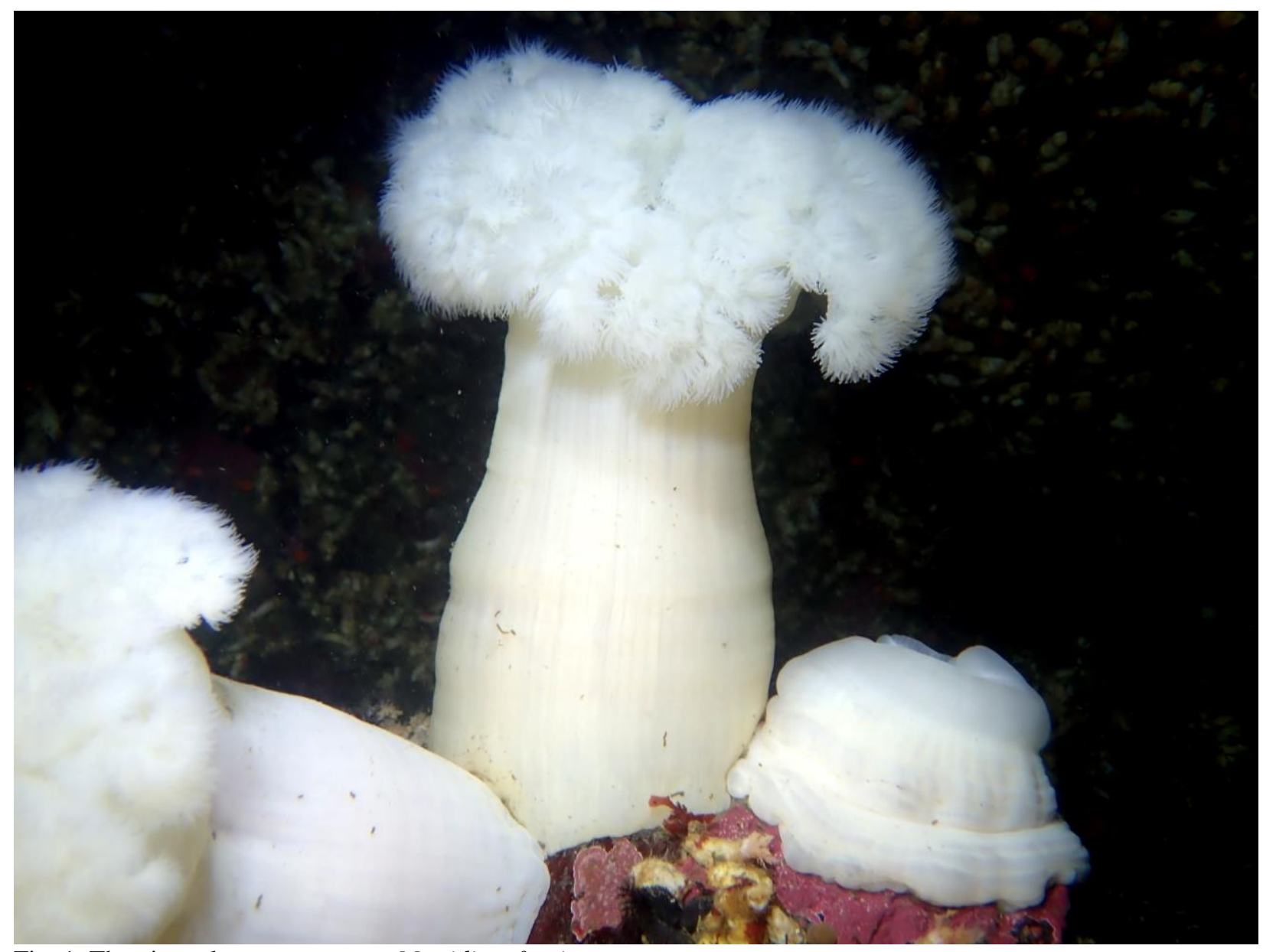

Fig. 1. The giant plumose anemone Metridium farcimen.

\section{MATERIALS AND METHODS}

\section{$\underline{\text { Sample collection and DNA isolation }}$}

Plankton communities were quantified by sampling the plankton at three sites within the San Juan Archipelago: adjacent the floating docks of the Friday Harbor Laboratories' (FHL; Friday Harbor, WA, USA, $\left.48.5452^{\circ} \mathrm{N}, 123.0124^{\circ} \mathrm{W}\right) ; 280 \mathrm{~m}$ southeast of the docks $\left(48.5436^{\circ} \mathrm{N}\right.$, $\left.123.0100^{\circ} \mathrm{W}\right)$; and in the San Juan Channel $\left(48.5490^{\circ} \mathrm{N}, 122.9924^{\circ} \mathrm{W}\right), 1.5 \mathrm{~km}$ northeast of the docks. The docks are in an embayment, while San Juan Channel experiences intense tidal flushing and mixing. Samples were taken during an ebb tide between 1:00 and 2:30 pm on August 4, 2016, 
a season when plankton is highly diverse. Two simultaneous plankton tows were performed at each site at 1-m depth. Each pair of tows included an 80- $\mu \mathrm{m}$ mesh size net to capture a broad range of plankton and a 330- $\mu \mathrm{m}$ mesh size net to capture large zooplankters. Both plankton nets were 50 $\mathrm{cm}$ wide, and approximately $98 \mathrm{~m}^{3}$ (125 m long tow) of water was sampled. Samples were immediately preserved in 50-mL falcon tubes in $95 \%$ ethanol in the field and kept at $-20{ }^{\circ} \mathrm{C}$ in the laboratory. Falcon tubes were centrifuged at $2000 \mathrm{x} g$ for eight minutes at room temperature to pelletize planktonic particles and remove ethanol. The pellet was homogenized with a mortar and pestle, and the whole tissue homogenate was used for DNA extraction using the MoBIO PowerMax ${ }^{\circledR}$ DNA Isolation Kit following manufacturer's instructions.

Sixteen M. farcimen were collected from the floating docks at FHL by hand one hour after the plankton tows. All collected anemones were within 20 meters of one another at $<1 \mathrm{~m}$ depth. Anemones were kept in seawater on ice until gut contents could be extracted (between 0.5 and 3 $\mathrm{hr}$ following collection). Material attached to the aboral end of the anemones was carefully removed and discarded. In the laboratory, anemones were bisected allowing efficient extraction of gut contents. Material extracted from the gut consisted of partially digested food, copious amounts of mucus, mesenteries, acontia (a structure for agonistic behaviors), and some gonadal tissue in sexually mature individuals. Large food particles (e.g., hydromedusae) were cut up into small pieces to facilitate later grinding. Gut contents were rinsed with $95 \%$ ethanol in a $45-\mu \mathrm{m}$ mesh net to remove excess mucus. Ethanol rinses dissolved anemone mucus more efficiently than seawater. Material within the $45-\mu \mathrm{m}$ mesh net was further massaged to break up large pieces. During this process, there is a risk of losing partially digested items that lack exoskeletons. The resulting samples were transferred into sterile sample tubes with $95 \%$ ethanol and kept at $-20{ }^{\circ} \mathrm{C}$ overnight. As there were still large particles within the sample, samples were centrifuged at $2000 \mathrm{x} g$ for eight minutes at $20{ }^{\circ} \mathrm{C}$, the supernatant was decanted, and the pellet was ground up within a mortar and pestle into a fine paste. The paste was placed back into another sterile tube with $95 \%$ ethanol, centrifuged at $2000 \mathrm{x} \mathrm{g}$ for eight minutes at $20^{\circ} \mathrm{C}$, and the supernatant was decanted. The whole pellet of each sample was used for DNA extraction using the MoBIO PowerSoil@ DNA Isolation Kit following manufacturer's instructions. Genomic DNA for both plankton and anemone samples were quantified with a Qubit fluorimeter and diluted to $10 \mathrm{ng} / \mu \mathrm{L}$.

\section{$\underline{P C R}$ and Library Preparation}

We used a hierarchical tagging approach with a combination of randomly-assigned tailed PCR primers and single indexed Illumina Y-adapters to sequence all samples in a single Illumina MiSeq run. Three PCR replications were performed per sample. DNA amplification was confirmed on $1.5 \%$ gel electrophoresis and then triplicates were pooled. DNA was purified using Solid Phase Reversible Immobilization beads to remove primers, primer dimers, salts and deoxynucleoside triphosphates (dNTPs). DNA samples from the 16 anemones and six plankton samples were used to amplify a highly variable fragment ( $313 \mathrm{bp})$ of the mitochondrial Cytochrome c oxidase subunit I (COI) region with the PCR primers mlCOIintF and jgHCO2198 (Geller, Meyer, Parker, \& Hawk, 2013; Leray, Yang, et al., 2013). Despite some amplification bias, this set of primers generates useful estimates of relative abundance (Leray \& Knowlton, 2015). PCR reactions were performed in a total volume of $20.0 \mu \mathrm{L}$, containing $13.2 \mu \mathrm{L}$ of nuclease free water, $2.0 \mu \mathrm{L}$ of Clontech 10X Advantage 2 PCR buffer (Takara Bio Inc., Kusatsu, JP), 1.0 $\mu \mathrm{L}$ of mlCOIintF $(10 \mu \mathrm{M}), 1.0 \mu \mathrm{L}$ of jgHCO2198 $(10 \mu \mathrm{M}), 1.4 \mu \mathrm{L}$ of dNTP, $0.4 \mu \mathrm{L}$ of Clontech 50X Advantage 2 (Takara Bio Inc., Kusatsu, JP), and $1.0 \mu \mathrm{L}$ (10 ng) of DNA. The reactions were incubated in a Biometra T3 thermocycler (Analytik Jena, Jena, DE), starting with 5 min of 
denaturation at $95^{\circ} \mathrm{C}$, followed by 35 cycles of $30 \mathrm{~s}$ at $95{ }^{\circ} \mathrm{C}, 30 \mathrm{~s}$ at $48{ }^{\circ} \mathrm{C}$, and $45 \mathrm{~s}$ at $72{ }^{\circ} \mathrm{C}$, with a final extension of $72{ }^{\circ} \mathrm{C}$. A negative PCR control and extraction control were performed to test whether the reagents were free of contaminants; both were negative for contamination. Purified PCR products were quantified using an Invitrogen Qubit ${ }^{\mathrm{TM}}$ fluorimeter and then diluted to 30 $\mathrm{ng} / \mu \mathrm{L}$. The PCR products of samples amplified with different tailed primers were pooled before library prep as detailed by Leray, Agudelo, Mills, and Meyer (2013) and Leray, Haenel, and Bourlat (2016). Samples were prepared for sequencing with the Illumina TruSeq DNA PCR-free LT Library Prep Kit, which includes end-repair and dA-tailing chemistry, and then ligated with adapters.

\section{$\underline{\text { Bioinformatics }}$}

Analysis of the sequence data followed the exact same protocol described in Nguyen et al. (2020). Sequences were demultiplexed and Illumina adapters were trimmed using Flexbar (Roehr, Dieterich, \& Reinert, 2017). DADA2 (Callahan, McMurdie, \& Holmes, 2017; Callahan et al., 2016) was then used to remove primers, discard low quality sequences and infer exact Amplicon Sequence Variants (ASVs) using the following parameters: $\operatorname{maxN}=0$, $\operatorname{maxEE}=\mathrm{c}(2,2)$, truncQ $=10$, trimLeft $=26$. DADA2 uses sequence quality scores and abundance information to generate an error model that best fit the data, and subsequently uses the error model to infer ASVs. ASVs, which can differ by as little as one nucleotide, were clustered into operational taxonomic units (OTUs) at a 97\% identity threshold using VSEARCH (Rognes, Flouri, Nichols, Quince, \& Mahé, 2016). To further improve estimates of alpha and beta diversity, spurious OTUs were removed using the LULU algorithm (Frøslev et al., 2017) (parameters: minimum ratio type = "min", minimum ratio $=1$, minimum match $=84$, minimum relative co-occurrence $=0.95$ ). This tool, which uses sequence similarity and co-occurrence patterns, was shown to reduce taxonomic redundancy and improve similarity with the true taxonomic composition of test samples (Frøslev et al., 2017).

Taxonomic names were assigned to each remaining OTU using an iterative approach. First, BLASTn searches were used to compare one representative sequence of each OTU to a database of northeast Pacific DNA barcodes. Many of these species were collected off the floats near the source of $M$. farcimen. An OTU was considered to match a local barcode when the level of sequence similarity was higher than $98 \%$. Second, unidentified OTUs were assigned taxonomic information using the Bayesian Least Common Ancestor Taxonomic Classification method (BLCA, Gao, Lin, Revanna, \& Dong, 2017) against a curated database of metazoan mitochondrial gene sequences (Midori-Unique v20180221 available at www.reference-midori.info, Machida, Leray, Ho, \& Knowlton, 2017). Assignments with less than 50\% confidence were not taken into account. Third, the numerous OTUs that remained unidentified using BLCA were compared to the whole NCBI NT database (May 2018) using BLAST searches (word size $=7$; max e-value $=5 \mathrm{e}-$ 13) and assigned the taxonomy of the lowest common ancestor of the first 100 hits.

\section{$\underline{\text { Statistical Analyses }}$}

Samples with over 95\% M. farcimen sequences and less than 7000 amplified sequences were dropped from the analysis. It was assumed that these individuals were either not feeding at the time of collection or prey sequences were hidden by the abundant co-amplification of $M$. farcimen sequences leading to insufficient data to categorize diet. Remaining gut content samples (12 of 16) and the plankton samples were rarified to the lowest number of sequences (7268 
sequences). An unequal number of sequences can affect estimates of diversity due to the positive relationship between sample size and number of OTUs. This rarefied dataset was used for all further analyses. All data were analyzed in R version 3.5.2 with the vegan 2.5-4 package (Oksanen et al., 2019; R Core Team, 2018).

To illustrate the sequencing effort, rarefaction curves were built for each for each treatment (i.e., gut contents and the two plankton sizes). A plateauing curve indicates an exhaustive sampling effort.

In this study, richness was defined as the number of different OTUs or taxa within a sample or treatment. Abundance was defined as the number of sequences within a sample or treatment. Evenness was defined as the similarity of frequencies of the abundances of OTUs within a treatment. The incidence of an OTU was defined as the fraction of samples or treatments containing that OTU. Mean evenness for each treatment was calculated using Pielou's evenness index (Pielou, 1966).

Matrices of community dissimilarity based on the Bray-Curtis index were created using both number of sequences and presence/absence of OTUs (i.e., the Sørensen index). Differences between diet composition of $M$. farcimen $(\mathrm{n}=12)$ and $80-\mu \mathrm{m}(\mathrm{n}=3)$ and 330- $\mu \mathrm{m}(\mathrm{n}=3)$ filtered plankton communities were tested using permutational multivariate analyses of variance (PERMANOVA, Anderson, 2001) with 9999 permutations. Patterns of species composition were visualized in two-dimensional space using non-metric multidimensional scaling ordination plots (nMDS) with 9999 permutations. Similarity percentage analysis (SIMPER) were used to determine what OTUs were significantly contributing to the Bray-Curtis dissimilarities calculated between groups of samples (Clarke, 1993).

\section{RESULTS}

A total of 3,109,361 high-quality metazoan sequences passed the quality controls with an average of 101,000 sequences per plankton sample and an average of 12,500 non-Metridium sequences for $M$. farcimen gut content samples. Four $M$. farcimen gut content samples did not provide a sufficient number of sequences $(<7000)$ and were dropped from further analyses, leaving 12 samples. All further results will be reported using the rarefied dataset. The rarefied dataset had 438 OTUs. Among these, 126 OTUs (29\% of all OTUs) were identified to species, 381 OTUs (87\% of all OTUs) were identified to at least the phylum level, and 57 OTUs (13\% of all OTUs) were unidentified metazoans. 174 OTUs (40\% of total OTUs) were identified using the Pacific northeast barcode database with 137 of the OTUs being identified to species. Rarefaction curves for both plankton and $M$. farcimen plateaued, which indicates that a sufficient number of sequences was obtained to estimate richness and composition of each sample (Fig. 2).

$M$. farcimen gut contents were richer in total (356 OTUs) than either the $80-\mu \mathrm{m}$ filtered plankton (160 OTUs) or the 330- $\mu$ m filtered plankton (97 OTUs). Individual gut contents were less rich on average (74 OTUs) than individual $80-\mu \mathrm{m}$ filtered plankton samples (91 OTUs) and richer than the individual 330- $\mu \mathrm{m}$ filtered plankton samples (53 OTUs). The 80 and 330- $\mu \mathrm{m}$ filtered plankton samples were more even ( 0.64 and 0.68 , respectively) than the gut contents 


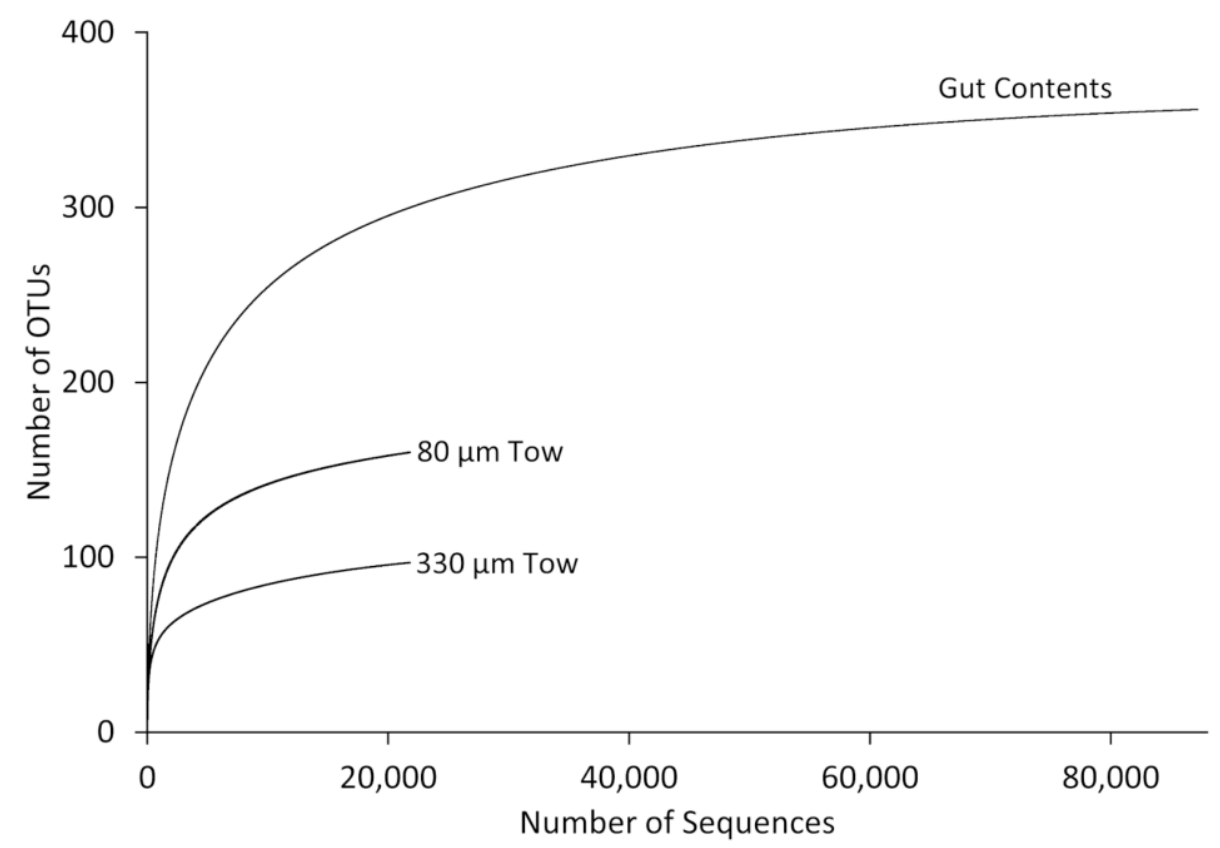

Fig. 2. Rarefaction curves to evaluate the completeness of the sequencing effort at describing the diversity of dietary items in the gut contents of Metridium farcimen and in nearby plankton samples using two different mesh sizes. All curves plateaued which indicates that this sampling was sufficient.

(0.57). Mean incidence was lowest in the gut contents (21\%) and higher in the 80 and 330- $\mu \mathrm{m}$ filtered plankton (57\% and 54\%, respectively).

The gut contents of $M$. farcimen contained on average 15 classes belonging to 10 animal phyla (Supp. Table 1). Metridium farcimen diet contents were primarily made up of arthropods (52\% of sequences), especially crabs (presumably larvae) hat this sampling was sufficient, barnacles (larvae or molts), copepods, and insects (Supp. Table 2). Hexanauplia was the most diverse class for both the gut contents and the $80-\mu \mathrm{m}$ and $330-\mu \mathrm{m}$ filtered plankton samples (15, 16, and 9 OTUs, respectively) and had the highest proportion of sequences for all three sample types $(22 \%, 38 \%$, and $33 \%$, respectively, Supp. Table 1). The class with the highest incidence within the gut contents of anemones was Hexanauplia (Supp. Table 3). Overall, metabarcoding of gut contents detected many more taxonomic groups than were found in previous conventional visual dietary analysis of Metridium spp. conducted by Purcell (1977), Sebens (1981), or Sebens and Koehl (1984). On average, eight metazoan classes were identified in visual identification methods (Purcell, 1977; Sebens, 1981; Sebens \& Koehl, 1984) whereas 27 classes were found using metabarcoding (Table 1). 
Table 1. Comparison of diet composition for Metridium species from previous studies and this effort.

\begin{tabular}{|c|c|c|c|c|c|c|}
\hline Phylum & Class & $\begin{array}{l}\text { Purcell } 1977 \\
- \text { M. senile }\end{array}$ & $\begin{array}{c}\text { Purcell } 1977 \\
-M . \\
\text { farcimen }\end{array}$ & $\begin{array}{c}\text { Sebens } 1981 \\
-M . \\
\text { farcimen }\end{array}$ & $\begin{array}{l}\text { Sebens and } \\
\text { Koehl } 1984 \\
\text { - M. senile }\end{array}$ & $\begin{array}{c}\text { This Study } \\
-M . \\
\text { farcimen }\end{array}$ \\
\hline Annelida & Polychaeta & $15 \%$ & $15 \%$ & $1 \%$ & & $14 \%$ \\
\hline \multirow[t]{6}{*}{ Arthropoda } & Arachnida & & & & Present & Present \\
\hline & Branchiopoda & & & & Present & $4 \%$ \\
\hline & Hexanauplia & $45 \%$ & $57 \%$ & $87 \%$ & $14 \%$ & $31 \%$ \\
\hline & Insecta & & & & & $14 \%$ \\
\hline & Malacostraca & Present & Present & $4 \%$ & $65 \%$ & $11 \%$ \\
\hline & Ostracoda & Present & & & $1 \%$ & $7 \%$ \\
\hline Bryozoa & Gymnolaemata & Present & $1 \%$ & $1 \%$ & Present & $3 \%$ \\
\hline Chaetognatha & Sagittoidea & & & & & Present \\
\hline \multirow[t]{2}{*}{ Chordata } & Actinoptergyii & & & & & Present \\
\hline & Ascidiacea & & & & $6 \%$ & Present \\
\hline \multirow[t]{4}{*}{ Cnidaria } & Anthozoa & & & & & Present \\
\hline & Hydrozoa & & & & $12 \%$ & $2 \%$ \\
\hline & Scyphozoa & & & & & Present \\
\hline & Staurozoa & & & & & Present \\
\hline Ctenophora & Tentaculata & & & & & $1 \%$ \\
\hline \multirow[t]{4}{*}{ Echinodermata } & Asteroidea & & & $1 \%$ & & \\
\hline & Echinoidea & & & & & Present \\
\hline & Holothuroidea & & & & & $1 \%$ \\
\hline & Ophiuroidea & & & & & Present \\
\hline \multirow{3}{*}{ Mollusca } & Bivalvia & $34 \%$ & $30 \%$ & $1 \%$ & & $2 \%$ \\
\hline & Gastropoda & $6 \%$ & $2 \%$ & $1 \%$ & & $2 \%$ \\
\hline & Polyplacophora & & & & & Present \\
\hline Nematoda & Chromadorea & Present & Present & & Present & Present \\
\hline \multirow[t]{2}{*}{ Nemertea } & Hoplonemertea & & & & & Present \\
\hline & Pilidiophora & & & & & Present \\
\hline Platyhelminthes & Rhabditophora & & & & & Present \\
\hline Porifera & Demospongiae & & & & Present & $4 \%$ \\
\hline Rotifera & Monogononta & & & & & $3 \%$ \\
\hline
\end{tabular}

Note: Non-metazoan and unidentified categories (e.g., eggs and embryos) were excluded. Purcell (1977) and Sebens (1981) used relative abundance, Sebens and Koehl (1984) used relative biomass, and we used relative number of sequences. Values less than $0.5 \%$ are denoted as "Present".

There was a significant difference between the communities in the $330-\mu \mathrm{m}$ plankton samples and the gut samples for both number of sequences (PERMANOVA, $F_{2,15}=1.93, \mathrm{R}^{2}=$ $0.20, p<0.001$ ) and presence/absence (PERMANOVA, $F_{2,15}=2.44, \mathrm{R}^{2}=0.25, p<0.001$, Fig. 3 5 ). There were significant differences between the 80- $\mu \mathrm{m}$ filtered plankton sample and the gut contents for both number of sequences (PERMANOVA, $F_{1,13}=1.31, \mathrm{R}^{2}=0.11, p=0.011$ ) and presence/absence (PERMANOVA, $F_{2,15}=1.72, \mathrm{R}^{2}=0.12, p=0.027$ ). Nineteen and 14 OTUs contributed significantly to the difference between gut content and plankton samples $(80-\mu \mathrm{m}$ and 330- $\mu \mathrm{m}$, respectively) (SIMPER, $\mathrm{p}<0.05$, Supp. Table 4-5). All OTUs that differed had higher relative abundances in the plankton than in the gut contents, none had lower abundances. The corrugated clam Humilaria kennerleyi (Reeve, 1863), the hydrozoan Clytia hemisphaerica (Linnaeus, 1767), the brittle star Ophiopholis kennerlyi Lyman, 1860, and the peanut worm Phascolosoma agassizii Keferstein, 1866 were all more than 25 times less abundant, relative to other OTUs, in the gut contents compared to the $80-\mu \mathrm{m}$ filtered plankton. The speckled sanddab Citharichthys stigmaeus Jordan \& Gilbert, 1882, the periwinkle Littorina scutulata Gould, 1849, 

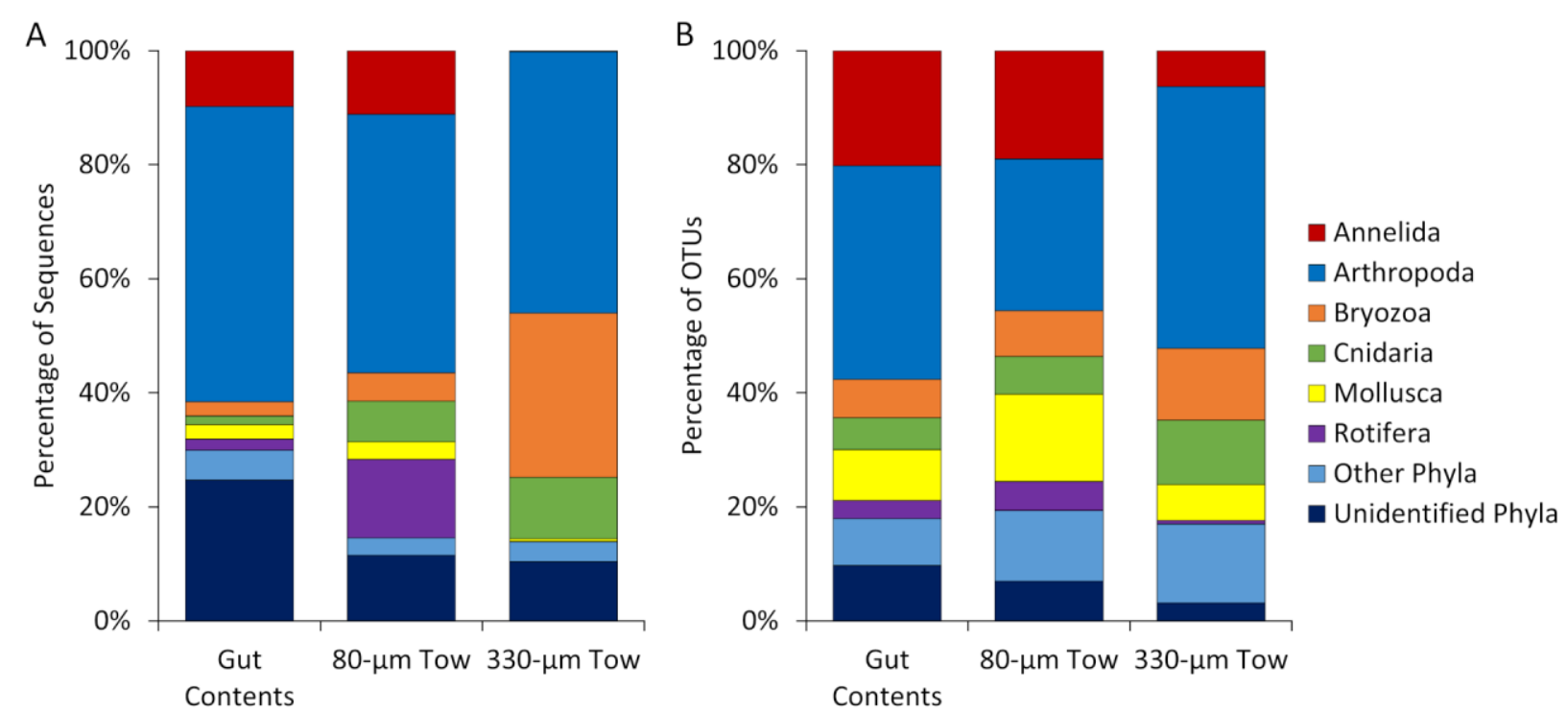

Fig. 3. Percentage of (A) sequences and (B) OTUs of major phyla in Metridium farcimen gut contents and nearby 80 and 330- $\mu \mathrm{m}$ filtered plankton samples. There were significant differences between the relative abundance of sequences of each community and presence/absence of OTUs (PERMANOVA, $\mathrm{p}<0.001$ ).

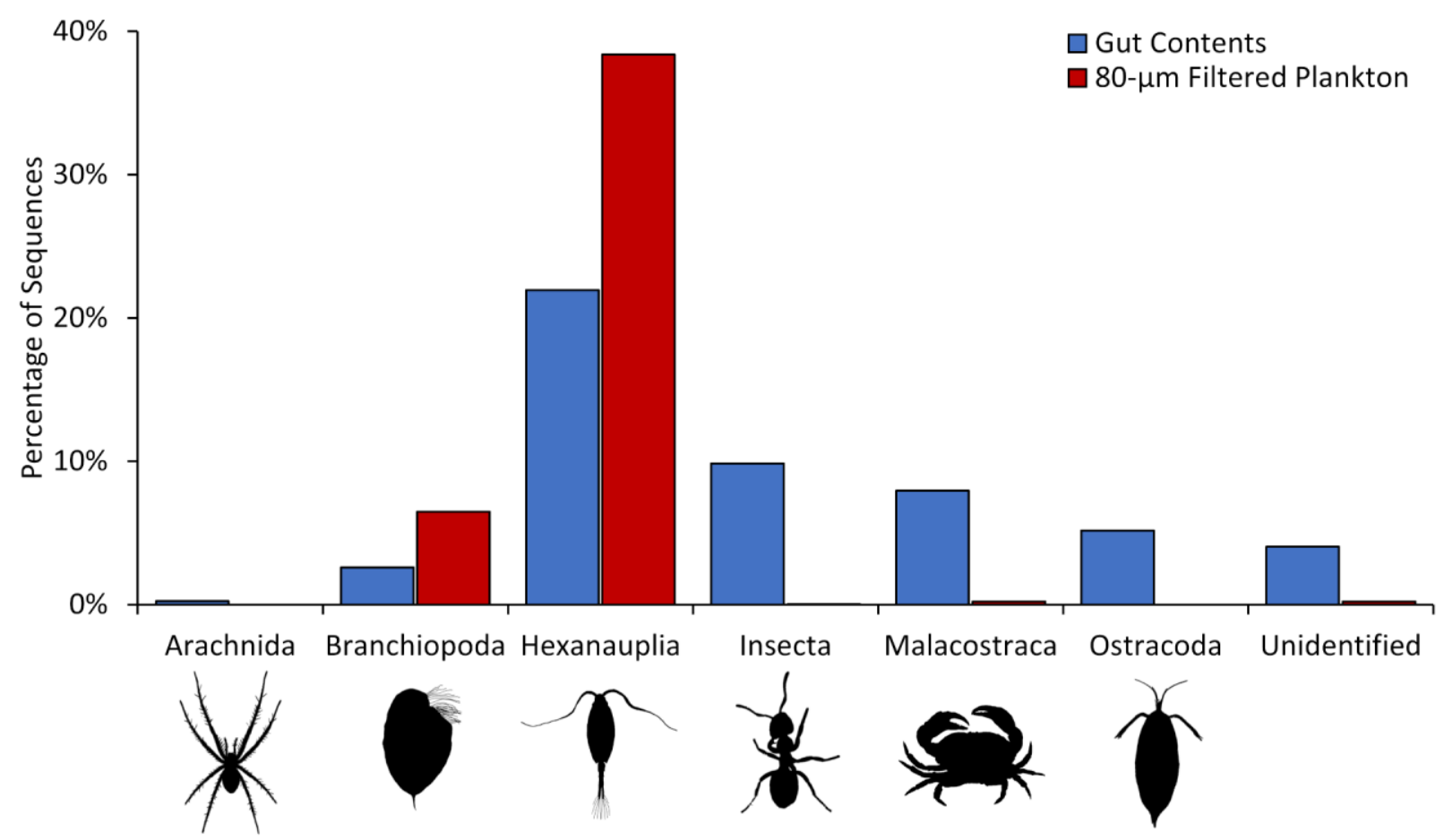

Fig. 4. Percentage of sequences of the arthropod classes within the phylum Arthropoda in Metridium farcimen gut contents and nearby $80-\mu \mathrm{m}$ filtered plankton samples.

the bryozoan Membranipora membranacea (Linnaeus, 1767), and the hydrozoan $C$. hemisphaerica were all over 70 times less abundant, relative to other OTUs, in the gut contents compared to the $330-\mu \mathrm{m}$ filtered plankton. 

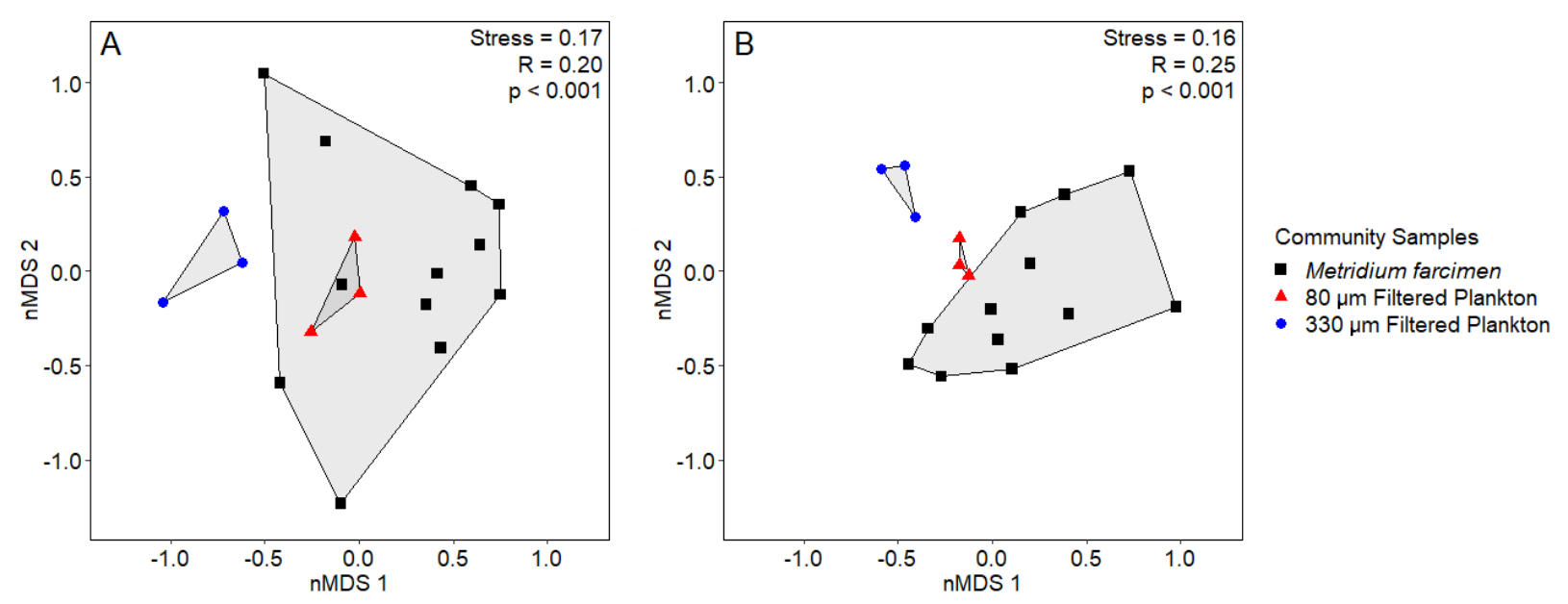

Fig. 5. Non-metric multidimensional scaling ordination (nMDS) of (A) number of sequences and (B) presence/absence of OTUs for gut contents of Metridium farcimen and nearby plankton samples. Each point represents one sample (plankton tow or gut content). Permutational analysis of variance (PERMANOVA) significance levels are indicated. There were significant differences between the diet of M. farcimen and nearby plankton samples.

\section{DISCUSSION}

Overall, M. farcimen gut contents held comparable richness to plankton tows on a persample basis (mean 71 vs 94/53 OTUs for 80/330 um tows), but held more total diversity (Fig. 2) indicating substantial greater intersample variability. This indicates highly variability in feeding among anemones within $20 \mathrm{~m}$ of one another, highlighting the small-scale spatial and temporal heterogeneity in zooplankton availability. A likely reason for this is that in addition to feeding on plankton, $M$. farcimen also captures many benthic taxa that wash off the docks.

It is well known that zooplankton are temporally variable, even at short timescales (Marques, Pardal, Mendes, \& Azeiteiro, 2011; Rodríguez et al., 2000). For example, to exclude the temporal variation component while additionally avoiding the issue of variable rates of digestion, Hansson (2006) released and recaptured lab-starved scyphomedusae and then examined what they had consumed over 20 minutes. This method could be adapted to work with anemones and other benthic suspension feeders by starving them in a lab, and, in the case of anemones, deploying them on panels in the field.

Results suggest diet selectivity in M. farcimen as was also found by Sebens and Koehl (1984), but contrary to what was found by Purcell (1977). Sebens and Koehl (1984) found that Metridium senile (Linnaeus, 1761) preferentially consumed barnacle cyprids, ascidian larvae, and amphipods, and avoided eggs, copepods, and ostracods, compared to availability. In our study, none of the prey species were significantly more common in the diet of M. farcimen, but several were less common (Supp. Table 4-5), suggesting that it was unable to detect or capture them. Dietary selectivity in $M$. farcimen seems to be more dependent on prey escape capabilities than predator preferences; this has also been observed in other anthozoans (Sebens, Vandersall, Savina, \& Graham, 1996). This result may seem surprising given the larger total richness in the diet of anemones, but individual gut content richness was lower than the $80-\mu \mathrm{m}$ filtered plankton and 
mean incidence was half of both plankton samples. While it is unknown how some potential prey species avoid predation, Heidelberg, Sebens, and Purcell (1997) showed that some, but not all, zooplankters can detect passive suspension feeders in moving water and subsequently avoid predation. In addition, they showed that very small prey (e.g., nauplii) were less susceptible to predation. This may be because nematocyst discharge is affected by both chemical cues and mechanical stimulation (Thorington \& Hessinger, 1988; Watson \& Hessinger, 1988). Larger prey is more likely to impact tentacles at a higher force, increasing capture probability through mechanical or surface chemical detection and consequently eliciting a nematocyst response.

The diet of M. farcimen was compositionally different from the diets found by both Purcell (1977) and Sebens (1981). These discrepancies may be partially explained by spatiotemporal differences among these studies locations. Purcell (1977) worked in Monterey, CA on M. farcimen associated with pilings at $8 \mathrm{~m}$ depth, while Sebens (1981) worked in Harper, WA, farther into the same sound as this study, but on subtidal pilings at $3 \mathrm{~m}$ below the surface. Unlike previous morphological dietary analysis (Purcell, 1977; Sebens, 1981), our results show a high relative abundance of demosponge and rotifers. The discrepancy is likely caused by the difficulty in identifying these groups with conventional visual techniques.

While Hexanauplia was the most diverse, rich, and abundant groups in the gut contents, likely because of its high diversity, richness, and abundance in the plankton (Supp. Table 1), we also found a high relative abundance of insects and ostracods in the gut contents (Table 1, Fig. 34). The most abundant insect prey (98\% of insect sequences) was the pale-legged field ant Lasius pallitarsis Emery, 1893 (100\% similarity match to the reference sequence GenBank Accession JN292076). This ant species has mating flights in August (Nonacs, 1990), the same month this study was conducted. It seems that $M$. farcimen, when associated with floating docks, may be getting a significant portion of their diet from episodic input from the nearby terrestrial environment. Strong tidal currents and mixing, however, could provide this resource to shallow subtidal populations on natural rock surfaces as well. This result highlights the need for further sampling across a broader temporal and spatial scale and across depth to better understand where $M$. farcimen and other benthic suspension feeders are deriving their energy.

Amplicon sequence variants were clustered into OTUs if they were $97 \%$ similar. This can lead to genetically diverse species being clustered into more than one OTU. In several cases, among our samples, sequences classified into different OTUs were mapped to the same species. This implies either that these named species are complexes of multiple cryptic species or that they hold $>3 \%$ intraspecific variation, something this study cannot determine. Species with more than one OTU delineated were the bryozoans Celloporella hyalina (Linnaeus, 1767) and $M$. membranacea, the hydrozoan Obelia longissima (Pallas, 1766), the Pacific littleneck clam Leukoma staminea (Conrad, 1837), the sharp nose crab Scyra acutifrons Dana, 1851, the sea gooseberry Pleurobrachia bachei A. Agassiz, 1860, and the syllid worm Syllis elongata (Johnson, 1901).

DNA metabarcoding is an efficient method for identifying even partially digested gut contents of animals. However, the results can only be ecologically interpreted if sequences can be matched to taxonomic groups. Building libraries of reference DNA barcodes is time consuming but essential. Metabarcoding has its own limitations that have been reviewed before (de Sousa, Silva, \& Xavier, 2019; Deagle et al., 2019). For example, it does not indicate the life stage of prey organisms, while traditional techniques can. It is also semi-quantitative, whereas visual methods can provide absolute counts or biomass. Therefore, we recommend pairing traditional techniques to identify major patterns and metabarcoding to identify the microscopic and partially digested 
prey items for future intensive studies. We also recommend either using starved animals or sampling the available plankton over a longer time period that best correspond with their prey retention time during digestion.

This work provides important insight into the diet of a competitively dominant sea anemone. Metabarcoding showed that these animals captures a wider range of prey than previously suspected based on conventional visual analysis. The surprising terrestrial input into the diet of $M$. farcimen highlights the need to consider land-sea interactions in trophic models.

\section{ACKNOWLEDGEMENTS}

This work was completed with permission from the director of Friday Harbor Laboratories (FHL). We were funded by the Patricia L. Dudley Endowment for FHL (awarded to CDW), the Kenneth P. Sebens Endowed Student Support Fund (awarded to CDW), the Richard and Megumi Strathmann Fellowship (awarded to CDW), the Robert T. Paine Experimental and Field Ecology Award Fellowship (awarded to CDW), and the FHL Marine Science Fund and Research Fellowship Endowment (both awarded to CDW). We thank the FHL director, faculty, and staff for laboratory space and logistical support; C. Alexandra, A. Ames, M. Ferguson, T. Ferreira, M. Hoban, K. Larkin, K.M. Markello, and J.K. Perez for field and laboratory assistance, and E.R. Anderson, M.N. Dethier, D. Grünbaum, Á. Martínez-Quintana, R. McLachlan, J.L. Ruesink, K.P. Sebens, K.J. Tonra, and M. Turner for reading and commenting on the manuscript.

\section{AUTHOR CONTRIBUTIONS}

CDW, GP and ML conceived and designed the study and collected the data. CDW and BNN analyzed the sequence dataset. Visualizations, statistical analysis, and interpretation were done by CDW and ML. CDW wrote the manuscript.

\section{DATA ARCHIVING}

The demultiplexed and adapter trimmed FASTQ files can be accessed on the NCBI SRA under the BioProject accession number PRJNA682207.

\section{LITERATURE CITED}

Albaina, A., Aguirre, M., Abad, D., Santos, M., \& Estonba, A. (2016). 18S rRNA V9 metabarcoding for diet characterization: a critical evaluation with two sympatric zooplanktivorous fish species. Ecology and Evolution, 6(6), 1809-1824. doi:10.1002/ece3.1986

Anderson, M. J. (2001). A new method for non-parametric multivariate analysis of variance. Austral Ecology, 26(1), 32-46. doi:10.1111/j.1442-9993.2001.01070.pp.x

Aylagas, E., Borja, Á., \& Rodríguez-Ezpeleta, N. (2014). Environmental status assessment using DNA metabarcoding: towards a genetics based marine biotic index (gAMBI). PLoS ONE, 9(3), e90529. doi:10.1371/journal.pone.0090529 
Brandon-Mong, G.-J., Gan, H.-M., Sing, K.-W., Lee, P.-S., Lim, P.-E., \& Wilson, J.-J. (2015). DNA metabarcoding of insects and allies: an evaluation of primers and pipelines. Bulletin of Entomological Research, 105, 717-727. doi:10.1017/S0007485315000681

Browman, H. I., Kruse, S., \& O'Brien, W. J. (1989). Foraging behavior of the predaceous cladoceran, Leptodora kindti, and escape responses of their prey. Journal of Plankton Research, 11(5), 1075-1088. doi:10.1093/plankt/11.5.1075

Callahan, B. J., McMurdie, P. J., \& Holmes, S. P. (2017). Exact sequence variants should replace operational taxonomic units in marker-gene data analysis. The Isme Journal, 11, 26392643. doi:10.1038/ismej.2017.119

Callahan, B. J., McMurdie, P. J., Rosen, M. J., Han, A. W., Johnson, A. J. A., \& Holmes, S. P. (2016). DADA2: high-resolution sample inference from Illumina amplicon data. Nature Methods, 13, 581-583. doi:10.1038/nmeth.3869

Clarke, K. R. (1993). Non-parametric multivariate analyses of changes in community structure. Australian Journal of Ecology, 18(1), 117-143. doi:10.1111/j.1442-9993.1993.tb00438.x

Costello, J. H., \& Colin, S. P. (2002). Prey resource use by coexistent hydromedusae from Friday Harbor, Washington. Limnology and Oceanography, 47(4), 934-942. doi:10.4319/lo.2002.47.4.0934

Cucci, T. L., Shumway, S. E., Newell, R. C., Selvin, R., Guillard, R. R. L., \& Yentsch, C. M. (1985). Flow cytometry: A new method for characterization of differential ingestion, digestion and egestion by suspension feeders. Marine Ecology Progress Series, 24(1/2), 201-204.

Davies, B. R., Stuart, V., \& de Villiers, M. (1989). The filtration activity of a serpulid polychaete population (Ficopomatus enigmaticus) (Fauvel) and its effects on water quality in a coastal marina. Estuarine, Coastal and Shelf Science, 29(6), 613-620. doi:10.1016/02727714(89)90014-0

de Sousa, L. L., Silva, S. M., \& Xavier, R. (2019). DNA metabarcoding in diet studies: Unveiling ecological aspects in aquatic and terrestrial ecosystems. Environmental DNA, 1(3), 199214. doi:10.1002/edn3.27

Deagle, B. E., Thomas, A. C., McInnes, J. C., Clarke, L. J., Vesterinen, E. J., Clare, E. L., . . . Eveson, J. P. (2019). Counting with DNA in metabarcoding studies: How should we convert sequence reads to dietary data? Molecular Ecology, 28(2), 391-406. doi: $10.1111 / \mathrm{mec} .14734$

Defossez, J. M., \& Hawkins, A. J. S. (1997). Selective feeding in shellfish: size-dependent rejection of large particles within pseudofaeces from Mytilus edulis, Ruditapes philippinarum and Tapes decussatus. Marine Biology, 129(1), 139-147. doi:10.1007/s002270050154

Deiner, K., Bik, H. M., Mächler, E., Seymour, M., Lacoursière-Roussel, A., Altermatt, F., . . . Bernatchez, L. (2017). Environmental DNA metabarcoding: transforming how we survey animal and plant communities. Molecular Ecology, 26(21), 5872-5895. doi: $10.1111 / \mathrm{mec} .14350$

Dodson, S. I. (1974). Adaptive change in plankton morphology in response to size-selective predation: a new hypothesis of cyclomorphosis. Limnology and Oceanography, 19(5), 721 729. doi:10.4319/lo.1974.19.5.0721

Engström, J., Viherluoto, M., \& Viitasalo, M. (2001). Effects of toxic and non-toxic cyanobacteria on grazing, zooplanktivory and survival of the mysid shrimp Mysis mixta. Journal of 
Experimental Marine Biology and Ecology, 257(2), 269-280. doi:10.1016/S00220981(00)00339-7

Evans, N. T., Olds, B. P., Renshaw, M. A., Turner, C. R., Li, Y., Jerde, C. L., . . Lodge, D. M. (2016). Quantification of mesocosm fish and amphibian species diversity via environmental DNA metabarcoding. Molecular Ecology Resources, 16(1), 29-41. doi:10.1111/1755-0998.12433

Fancett, M. S. (1988). Diet and prey selectivity of scyphomedusae from Port Phillip Bay, Australia. Marine Biology, 98(4), 503-509. doi:10.1007/BF00391541

Fautin, D. G., Bucklin, A., \& Hand, C. (1989). Systematics of sea anemones belonging to genus Metridium (Coelenterata: Actiniaria), with a description of M. giganteum new species. Wasmann Journal of Biology, 47(1-2), 77-85.

Fautin, D. G., \& Hand, C. (2000). Metridium farcimen, the valid name of a common North Pacific sea anemone (Cnidaria: Actiniaria: Acontiaria). Proceedings of the Biological Society of Washington, 113(4), 1151-1161.

Frøslev, T. G., Kjøller, R., Bruun, H. H., Ejrnæs, R., Brunbjerg, A. K., Pietroni, C., \& Hansen, A. J. (2017). Algorithm for post-clustering curation of DNA amplicon data yields reliable biodiversity estimates. Nature Communications, 8(1188), 1-11. doi:10.1038/s41467-01701312-x

Gao, X., Lin, H., Revanna, K., \& Dong, Q. (2017). A Bayesian taxonomic classification method for 16S rRNA gene sequences with improved species-level accuracy. BMC Bioinformatics, 18(1), 247. doi:10.1186/s12859-017-1670-4

Geller, J., Meyer, C., Parker, M., \& Hawk, H. (2013). Redesign of PCR primers for mitochondrial cytochrome c oxidase subunit I for marine invertebrates and application in all-taxa biotic surveys. Molecular Ecology Resources, 13(5), 851-861. doi:10.1111/1755-0998.12138

Gili, J.-M., \& Coma, R. (1998). Benthic suspension feeders: their paramount role in littoral marine food webs. Trends in Ecology \& Evolution, 13(8), 316-321. doi:10.1016/S01695347(98)01365-2

Hand, C. (1955). The sea anemones of central California part III. The acontiarian anemones. Wasmann Journal of Biology, 13, 189-251.

Hansson, L. J. (2006). A method for in situ estimation of prey selectivity and predation rate in large plankton, exemplified with the jellyfish Aurelia aurita (L.). Journal of Experimental Marine Biology and Ecology, 328(1), 113-126. doi:10.1016/j.jembe.2005.07.002

Harms-Tuohy, C. A., Schizas, N. V., \& Appeldoorn, R. S. (2016). Use of DNA metabarcoding for stomach content analysis in the invasive lionfish Pterois volitans in Puerto Rico. Marine Ecology Progress Series, 558, 181-191. doi:10.3354/meps 11738

Heidelberg, K. B., Sebens, K. P., \& Purcell, J. E. (1997). Effects of prey escape and water flow on feeding by the scleractinian coral Meandrina meandrites. In H. A. Lessios \& I. G. MacIntyre (Eds.), Proceedings of the 8th International Coral Reef Symposium (pp. 10811086). Balboa, PA: Smithsonian Tropical Research Institute.

Ji, Y., Ashton, L., Pedley, S. M., Edwards, D. P., Tang, Y., Nakamura, A., . . Yu, D. W. (2013). Reliable, verifiable and efficient monitoring of biodiversity via metabarcoding. Ecology Letters, 16(10), 1245-1257. doi:10.1111/ele.12162

Jørgensen, B. B. (1980). Seasonal oxygen depletion in the bottom waters of a Danish fjord and its effect on the benthic community. Oikos, 34(1), 68-76. doi:10.2307/3544551 
Kimmerer, W. J., Gartside, E., \& Orsi, J. J. (1994). Predation by an introduced clam as the likely cause of substantial declines in zooplankton of San Francisco Bay. Marine Ecology Progress Series, 113(1/2), 81-93. doi:10.3354/meps113081

Koehl, M. A. R. (1977a). Effects of sea anemones on the flow forces they encounter. Journal of Experimental Biology, 69(1), 87-105.

Koehl, M. A. R. (1977b). Mechanical diversity of connective tissue of the body wall of sea anemones. Journal of Experimental Biology, 69(1), 107-125.

Koehl, M. A. R. (1977c). Mechanical organization of cantilever-like sessile organisms: Sea anemones. Journal of Experimental Biology, 69(1), 127-142.

Kozloff, E. N. (1973). Seashore Life of Puget Sound, the Strait of Georgia, and the San Juan Archipelago. University of Washington Press: Seattle, WA, USA.

Larson, R. J. (1991). Diet, prey selection and daily ration of Stomolophus meleagris, a filterfeeding scyphomedusa from the NE Gulf of Mexico. Estuarine, Coastal and Shelf Science, 32(5), 511-525. doi:10.1016/0272-7714(91)90038-D

Leray, M., Agudelo, N., Mills, S. C., \& Meyer, C. P. (2013). Effectiveness of annealing blocking primers versus restriction enzymes for characterization of generalist diets: unexpected prey revealed in the gut contents of two coral reef fish species. PLoS ONE, 8(4), e58076. doi:10.1371/journal.pone.0058076

Leray, M., Alldredge, A. L., Yang, J. Y., Meyer, C. P., Holbrook, S. J., Schmitt, R. J., . . Brooks, A. J. (2019). Dietary partitioning promotes the coexistence of planktivorous species on coral reefs. Molecular Ecology(ja), Accepted Manuscript. doi:10.1111/mec.15090

Leray, M., Haenel, Q., \& Bourlat, S. J. (2016). Preparation of amplicon libraries for metabarcoding of marine eukaryotes using Illumina MiSeq: the adapter ligation method. In S. J. Bourlat (Ed.), Methods in Molecular Biology: Marine Genomics Methods and Protocols (2016/07/28 ed., Vol. 1452, pp. 209-218). New York, NY, USA: Humana Press.

Leray, M., \& Knowlton, N. (2015). DNA barcoding and metabarcoding of standardized samples reveal patterns of marine benthic diversity. Proceedings of the National Academy of Sciences, 112(7), 2076. doi:10.1073/pnas.1424997112

Leray, M., Meyer, C. P., \& Mills, S. C. (2015). Metabarcoding dietary analysis of coral dwelling predatory fish demonstrates the minor contribution of coral mutualists to their highly partitioned, generalist diet. PeerJ, 3, e1047. doi:10.7717/peerj.1047

Leray, M., Yang, J. Y., Meyer, C. P., Mills, S. C., Agudelo, N., Ranwez, V., . . Machida, R. J. (2013). A new versatile primer set targeting a short fragment of the mitochondrial COI region for metabarcoding metazoan diversity: application for characterizing coral reef fish gut contents. Frontiers in Zoology, 10(1), 1-14. doi:10.1186/1742-9994-10-34

Machida, R. J., Leray, M., Ho, S.-L., \& Knowlton, N. (2017). Metazoan mitochondrial gene sequence reference datasets for taxonomic assignment of environmental samples. Scientific Data, 4, 170027. doi:10.1038/sdata.2017.27

Marques, S. C., Pardal, M. Â., Mendes, S., \& Azeiteiro, U. M. (2011). Using multitable techniques for assessing the temporal variability of species-environment relationship in a copepod community from a temperate estuarine ecosystem. Journal of Experimental Marine Biology and Ecology, 405(1), 59-67. doi:10.1016/j.jembe.2011.05.015

Nelson, M. L., \& Craig, S. F. (2011). Role of the sea anemone Metridium senile in structuring a developing subtidal fouling community. Marine Ecology Progress Series, 421, 139-149. doi:10.3354/meps08838 
Nguyen, B. N., Shen, E. W., Seemann, J., Correa, A. M. S., O’Donnell, J. L., Altieri, A. H., .. . Leray, M. (2020). Environmental DNA survey captures patterns of fish and invertebrate diversity across a tropical seascape. Scientific Reports, 10(1), 6729. doi:10.1038/s41598020-63565-9

Nielsen, J. M., Clare, E. L., Hayden, B., Brett, M. T., \& Kratina, P. (2018). Diet tracing in ecology: method comparison and selection. Methods in Ecology and Evolution, 9(2), 278-291. doi:10.1111/2041-210X.12869

Nonacs, P. (1990). Size and kinship affect success of co-founding Lasius pallitarsis queens. Psyche, 97(3-4), 217-228. doi:10.1155/1990/21379

Oksanen, J., Blanchet, F. G., Friendly, M., Kindt, R., Legendre, P., McGlinn, D., . . Wagner, H. (2019). vegan: Community Ecology Package (Version R package version 2.5-4). Retrieved from https://CRAN.R-project.org/package=vegan

Petersen, J. K. (2004). Grazing on pelagic primary producers - the role of benthic suspension feeders in estuaries. In S. L. Nielsen, G. T. Banta, \& M. F. Pedersen (Eds.), Estuarine Nutrient Cycling: The Influence of Primary Producers: The Fate of Nutrients and Biomass (pp. 129-152). Dordrecht, ZH, NL: Springer Netherlands.

Petersen, J. K., \& Riisgård, H. U. (1992). Filtration capacity of the ascidian Ciona intestinalis and its grazing impact in a shallow fjord. Marine Ecology Progress Series, 88(1), 9-17. doi:10.3354/meps088009

Pielou, E. C. (1966). The measurement of diversity in different types of biological collections. Journal of Theoretical Biology, 13, 131-144. doi:10.1016/0022-5193(66)90013-0

Purcell, J. E. (1977). The diet of large and small individuals of the sea anemone Metridium senile. Southern California Academy of Sciences, 76(3), 168.

R Core Team. (2018). R: A Language and Environment for Statistical Computing. Vienna, AT: R Foundation for Statistical Computing. Retrieved from https://www.R-project.org

Ricketts, E., Calvin, J., \& Hedgpeth, J. (1968). Between Pacific Tides. Palo Alto, CA, USA: Stanford University Press.

Riisgård, H. U. (1991). Suspension feeding in the polychaete Nereis diversicolor. Marine Ecology Progress Series, 70(1), 29-37. doi:10.3354/meps070029

Riisgård, H. U., Jürgensen, C., \& Clausen, T. (1996). Filter-feeding ascidians (Ciona intestinalis) in a shallow cove: implications of hydrodynamics for grazing impact. Journal of Sea Research, 35(4), 293-300. doi:10.1016/S1385-1101(96)90756-X

Riisgård, H. U., Poulsen, L., \& Larsen, P. S. (1996). Phytoplankton reduction in near-bottom water caused by filter-feeding Nereis diversicolor - implications for worm growth and population grazing impact. Marine Ecology Progress Series, 141, 47-54. doi:10.3354/meps 141047

Rodríguez, F., Fernández, E., Head, R. N., Harbour, D. S., Bratbak, G., Heldal, M., \& Harris, R. P. (2000). Temporal variability of viruses, bacteria, phytoplankton and zooplankton in the western English Channel off Plymouth. Journal of the Marine Biological Association of the United Kingdom, 80(4), 575-586. doi:10.1017/S0025315400002393

Roehr, J. T., Dieterich, C., \& Reinert, K. (2017). Flexbar 3.0 - SIMD and multicore parallelization. Bioinformatics, 33(18), 2941-2942. doi:10.1093/bioinformatics/btx330

Rognes, T., Flouri, T., Nichols, B., Quince, C., \& Mahé, F. (2016). VSEARCH: a versatile open source tool for metagenomics. PeerJ, 4, e2584. doi:10.7717/peerj.2584

Safi, K. A., Hewitt, J. E., \& Talman, S. G. (2007). The effect of high inorganic seston loads on prey selection by the suspension-feeding bivalve, Atrina zelandica. Journal of 
Experimental Marine Biology and Ecology, 344(2), 136-148. doi:10.1016/j.jembe.2006.12.023

Sebens, K. P. (1981). The allometry of feeding, energetics, and body size in three sea anemone species. Biological Bulletin, 161(1), 152-171. doi:10.2307/1541115

Sebens, K. P., \& Koehl, M. A. R. (1984). Predation on zooplankton by the benthic anthozoans Alcyonium siderium (Alcyonacea) and Metridium senile (Actiniaria) in the New England subtidal. Marine Biology, 81(3), 255-271. doi:10.1007/bf00393220

Sebens, K. P., Vandersall, K. S., Savina, L. A., \& Graham, K. R. (1996). Zooplankton capture by two scleractinian corals, Madracis mirabilis and Montastrea cavernosa, in a field enclosure. Marine Biology, 127(2), 303-317. doi:10.1007/BF00942116

Shick, J. M. (1991). A functional biology of sea anemones (First Edition ed.). London: Chapman \& Hall.

Shumway, S. E., Cucci, T. L., Newell, R. C., \& Yentsch, C. M. (1985). Particle selection, ingestion, and absorption in filter-feeding bivalves. Journal of Experimental Marine Biology and Ecology, 91(1), 77-92. doi:10.1016/0022-0981(85)90222-9

Suchman, C. L., \& Sullivan, B. K. (1998). Vulnerability of the copepod Acartia tonsa to predation by the scyphomedusa Chrysaora quinquecirrha: effect of prey size and behavior. Marine Biology, 132(2), 237-245. doi:10.1007/s002270050389

Taberlet, P., Coissac, E., Pompanon, F., Brochmann, C., \& Willerslev, E. (2012). Towards nextgeneration biodiversity assessment using DNA metabarcoding. Molecular Ecology, 21(8), 2045-2050. doi:10.1111/j.1365-294X.2012.05470.x

Thorington, G. U., \& Hessinger, D. A. (1988). Control of discharge of cnidae: Factors affecting discharge of cnidae. In D. A. Hessinger \& H. M. Lenhoff (Eds.), The Biology of Nematocysts (pp. 233-253). San Diego, CA, USA: Academic Press.

Valentini, A., Taberlet, P., Miaud, C., Civade, R., Herder, J., Thomsen, P. F., . . Dejean, T. (2016). Next-generation monitoring of aquatic biodiversity using environmental DNA metabarcoding. Molecular Ecology, 25(4), 929-942. doi:10.1111/mec.13428

Vedel, A. (1998). Phytoplankton depletion in the benthic boundary layer caused by suspensionfeeding Nereis diversicolor (Polychaeta): grazing impact and effect of temperature. Marine Ecology Progress Series, 163, 125-132. doi:10.3354/meps163125

Vedel, A., Andersen, B. B., \& Riisgård, H. U. (1994). Field investigations of pumping activity of the facultatively filter-feeding polychaete Nereis diversicolor using an improved infrared phototransducer system. Marine Ecology Progress Series, 103(1/2), 91-101. doi:10.3354/meps103091

Viitasalo, M., Flinkman, J., \& Viherluoto, M. (2001). Zooplanktivory in the Baltic Sea: A comparison of prey selectivity by Clupea harengus and Mysis mixta, with reference to prey escape reactions. Marine Ecology Progress Series, 216, 191-200. doi:10.3354/meps216191

Viitasalo, M., Kiørboe, T., Flinkman, J., Pedersen, L., W., \& Visser, A. W. (1998). Predation vulnerability of planktonic copepods: consequences of predator foraging strategies and prey sensory abilities. Marine Ecology Progress Series, 175, 129-142. doi:10.3354/meps175129

Watson, G. M., \& Hessinger, D. A. (1988). Localization of a purported chemoreceptor involved in triggering cnidae discharge in anemones. In D. A. Hessinger \& H. M. Lenhoff (Eds.), The Biology of Nematocysts (pp. 255-272). San Diego, CA, USA: Academic Press. 
Wells, C. D. (2019). Biology and ecology of hexacorallians in the San Juan Archipelago. (Doctor of Philosophy PhD Dis-sertation). University of Washington, Seattle, WA, USA.

Wells, C. D., \& Sebens, K. P. (2017). Individual marking of soft-bodied subtidal invertebrates in situ - A novel staining technique applied to the giant plumose anemone Metridium farcimen (Tilesius, 1809). PLoS ONE, 12(11), e0188263. doi:10.1371/journal.pone.0188263

Whitten, A. L., Marin Jarrin, J. R., \& McNaught, A. S. (2018). A mesocosm investigation of the effects of quagga mussels (Dreissena rostriformis bugensis) on Lake Michigan zooplankton assemblages. Journal of Great Lakes Research, 44(1), 105-113. doi:10.1016/j.jglr.2017.11.005

Young, C. M., \& Gotelli, N. J. (1988). Larval predation by barnacles: effects on patch colonization in a shallow subtidal community. Ecology, 69(3), 624-634. doi:10.2307/1941011

Yu, D. W., Ji, Y., Emerson, B. C., Wang, X., Ye, C., Yang, C., \& Ding, Z. (2012). Biodiversity soup: metabarcoding of arthropods for rapid biodiversity assessment and biomonitoring. Methods in Ecology and Evolution, 3(4), 613-623. doi:10.1111/j.2041-210X.2012.00198.x

Zamer, W. E. (1986). Physiological energetics of the intertidal sea anemone Anthopleura elegantissima - I. Prey capture, absorption efficiency and growth. Marine Biology, 92(3), 299-314. doi:10.1007/bf00392670 